(C) 2020, The Authors. Published by Elsevier Inc. and Fass Inc. on behalf of the American Dairy Science Association ${ }^{\circledR}$. This is an open access article under the CC BY-NC-ND license (http://creativecommons.org/licenses/by-nc-nd/4.0/).

\title{
Association between lameness risk assessment and lameness and foot lesion prevalence on dairy farms in Alberta, Canada
}

Michelle van Huyssteen, Herman W. Barkema, Steve Mason, and Karin Orsel*

Department of Production Animal Health, Faculty of Veterinary Medicine, University of Calgary, Calgary, AB, Canada, T2N 4N1

\begin{abstract}
Lameness is a detrimental health and welfare concern of dairy cattle with high prevalence in North American herds. As a practical and farm-specific approach toward its mitigation in Alberta, Canada, a score-based lameness risk assessment questionnaire (RAQ) was developed for veterinarians to conduct with their clients; however, its accuracy in identifying risk for lameness and hoof lesions has not been evaluated. Our objectives were to (1) provide an update on prevalence of lameness and hoof lesions in Alberta freestall herds, (2) validate the RAQ by determining the association between RAQ scores and the prevalence of herd lameness and herd lesions, and (3) determine the association between presence of common hoof lesions and lameness. For the first 2 objectives, 65 Alberta dairy farms were visited between March and October 2018 to collect a completed RAQ, hoof trimming records from their hoof trimmer, and video footage of the entire lactating herd. For the third objective, 10 participant herds were visited twice between November 2013 and June 2014 to take video footage of the entire lactating herd and collect hoof trimming records from their hoof trimmer within $48 \mathrm{~h}$ after video footage collection. Median herd-level lameness prevalence was $20 \%$ (range $=2-56 \%$ ), infectious lesion prevalence was $10 \%$ (range $=0-49 \%$ ), and noninfectious lesion prevalence was $15 \%$ (range $=2-39 \%$ ). Of cows that were lame, $93 \%$ had a lesion, whereas $21 \%$ of cows with a lesion were lame. Cows with an infectious and noninfectious lesion were, respectively, 1.5 and 3.1 times more likely to be lame than cows with no lesion. Total RAQ score and herd lameness prevalence were correlated $(r=0.26)$ and noninfectious RAQ score and noninfectious lesion prevalence were correlated $(\mathrm{r}$ $=0.45)$, whereas infectious RAQ score and infectious lesion prevalence were not. Cow-level mixed logistic regression models indicated no associations between any of the RAQ scores and presence of lameness or a hoof
\end{abstract}

Received October 30, 2019.

Accepted July 13, 2020.

*Corresponding author: karin.orsel@ucalgary.ca lesion. Lameness prevalence in Alberta remains high, indicative of a low adoption rate of mitigation strategies by producers. Improvement of the RAQ could allow for better reflection of lameness and lesions on farm and can be achieved through further risk factor analysis within the RAQ, which may result in removal or addition of questions as well as the adjustment of scores based on risk factors' strength of association with lameness and lesions.

Key words: dairy cattle, risk score, lameness control, evaluation

\section{INTRODUCTION}

Lameness is one of the largest health problems in the dairy industry worldwide. It has a major economic impact, negatively affecting milk production (Green et al., 2002; Reader et al., 2011), longevity (Booth et al., 2004), and reproductive performance (Machado et al., 2010; Chapinal et al., 2013). Additionally, due to its association with pain, lameness has a negative effect on welfare of dairy cattle (Whay and Shearer, 2017). Prevalence of moderate and severe lameness in freestall-housed herds is high on a global scale but can range in estimates depending on region. For instance, North American studies have reported estimates that range from 10 to 55\% (von Keyserlingk et al., 2012; Cook et al., 2016; Westin et al., 2016; Adams et al., 2017). Recent studies in Canada, including herds from Alberta, Ontario, Quebec, and the Maritimes, have reported prevalence estimates with a smaller range of 19 to $24 \%$ (Solano et al., 2015; Jewell et al., 2019). Although lameness detection remains a subjective measure partly because of a variety of locomotion scoring systems, the Canadian Dairy Code of Practice considers a lameness prevalence of $10 \%$ to be an acceptable upper limit (National Farm Animal Care Council, 2009). Although this limit considers only severe cases of lameness, the importance of including moderate cases must not be ignored; doing so further emphasizes the magnitude of this important health and welfare issue.

Risk factors for lameness are generally considered consistent with risk factors for hoof lesions due to the 
reported $90 \%$ association between lameness and hoof lesions (Murray et al., 1996). Lesions can be either infectious or noninfectious, and each type has its own unique risk factors that primarily arise from facility design of the barn and management of the herd. Herdlevel factors reported to be associated with infectious lesions, predominantly digital dermatitis (DD), are internal and external biosecurity practices, footbath design and management, and environmental cleanliness (Relun et al., 2013; Cook, 2017; Oliveira et al., 2017). Reported factors for lameness related to noninfectious lesions, including white line, sole ulcer, and hemorrhage, include stall comfort and stocking density, which both negatively affect lying time, and trauma-related factors such as floor slipperiness and sharp turns (Barker et al., 2010; Solano et al., 2015, 2016b).

The repeated findings of the same risk factors for lameness indicate that adoption rate of known control and prevention strategies by producers remains low. A potential reason is drastic underestimation of lameness in their herds (Leach et al., 2010; Cutler et al., 2017). Another reason could be lack of producer awareness of these risk factors being present on their farm. In some studies, exposure of producers to an on-farm assessment aiming to identify farm-specific risk factors increased uptake of mitigation strategies (Chapinal et al., 2014b; Morabito et al., 2017). There is increased interest in the development and implementation of intervention programs to support producers in the reduction of lameness. A lameness control program was tested for dairy heifers in a UK study but failed to see improvement due to limitations, including a lack of producer and veterinarian compliance to the program (Bell et al., 2009). A follow-up study that involved more commitment from producers and veterinarians did, however, observe effectiveness of an intervention control program with reduced prevalence (Main et al., 2012).

As an approach toward control and prevention of lameness in Alberta, a veterinarian-administered lameness risk assessment questionnaire (RAQ) was developed (Alberta Milk, 2016). Based on the existing knowledge of risk factors for lameness, the RAQ is a score-based questionnaire that the veterinarian conducts with the producer with an aim of identifying farm-specific risk related to herd management and facility design for infectious and noninfectious lesions followed by implementation of changes to reduce lameness in the herd. Although the RAQ is not based on risk factors for lesions specifically, it is assumed that these risk factors are shared due to the strong association between lameness and lesions; however, this assumption remains a recognized gap in knowledge. A higher cumulative score is indicative of increased risk of lameness in the herd and, if the RAQ is valid in its identification of on-farm risk, increased prevalence. However, the validity of the RAQ remains unknown and is an important step in the support of producers to provide a more targeted and farm-specific approach for lameness mitigation through directed intervention strategies that are based on the RAQ results.

The objectives of this study were, therefore, to determine the current prevalence of lameness and infectious and noninfectious lesions in Alberta freestall herds and validate the RAQ by determining the association of RAQ scores with herd lameness and lesion prevalence. Additionally, due to the RAQ's question content with presented risk factors being based on the high association between lameness and presence of a lesion, the third objective was to determine this association in Alberta freestall herds with a focus on common lesions and collectively as infectious and noninfectious lesions using data collected for a previous study (Solano et al., 2017).

\section{MATERIALS AND METHODS}

All data collection protocols and questionnaires were approved by the University of Calgary Animal Care Committee (AC17-0163 and AC13-0082) and Research Ethics Board (REB17-1522).

\section{Herd Selection}

For our first 2 objectives (study 1), to ensure representation of most dairy herds in Alberta, farm selection criteria included a herd size of $\geq 40$ lactating HolsteinFriesian cows housed in freestalls. In addition, eligible farms were enrolled in the CanWest DHI (Guelph, ON, Canada) milk recording program, had a professional hoof trimmer who was a member of the Western Canadian Certified Hoof Trimmers Association (WCCHTA), and were within reasonable driving distance $(\leq 5$ h) from the University of Calgary. Farms were excluded if they operated with automated milking systems or if the lactating herd had outdoor access for $>2 \mathrm{~h} / \mathrm{d}$.

Advertisement of the study was done through Alberta Milk (Edmonton, AB, Canada) for the recruitment of potential participants, where those who were interested $(\mathrm{n}=11)$ could contact the graduate student (MV) for more information. In addition, farms that had already completed an RAQ with their veterinarian as part of Alberta Milk's Lameness Reduction Initiative (LRI; n $=88$; Alberta Milk, 2016) and clients of participating WCCHTA hoof trimmers $(\mathrm{n}=109)$ were contacted by telephone to determine interest in participation and whether eligibility criteria were met. Given these crite- 
ria and willingness to participate, a convenience sample of 65 herds were enrolled in the study.

\section{Risk Assessment Questionnaire}

The RAQ comprised 9 sections: (1) general farm information, (2) farm biosecurity measures, (3) animalbased measures, (4) pregnant heifer facilities, (5) pregnant heifer management, (6) dry cow facilities, (7) dry cow management, (8) lactating cow facilities, and (9) lactating cow management. Within sections 2 to 9, multiple-choice questions were included related to the farm's risk for infectious or noninfectious lesions or causes of lameness. Answers for each question are associated with a weighted risk score based on evidentiary literature of the factor that is being assessed. The risk scores for each question sum to a total score for noninfectious and infectious causes of lameness in each section of the RAQ, with section scores adding to a total score for noninfectious and infectious causes of lameness. These 2 totals combined result in the total RAQ score. With this combined total RAQ score, it is important to note that the selected risk score for some questions contributes to both the infectious and noninfectious causes of lameness and is counted twice. Section 3 in the RAQ was not included in the score count due to these questions being related to national assessment participation and record keeping.

During the farm visit, sections of the RAQ related to management and biosecurity measures were completed based on answers supplied by the producer or dairy manager during an interview with the graduate student (MV). The temaining sections, related to facilities, were also completed by one person (the same student) based on direct observation and required measurements. For questions in the lactating cow facilities section, the pen with the highest number of cows was selected for assessment. Pens containing animals that were most distant from their expectant calving dates were selected for assessment of pregnant heifer facilities and dry cow facilities sections. If these pens were inaccessible, those in the close-up pen were selected for assessment. The RAQ is available online (https://www.dairyresearch .ca/file.php? filename $=/ \mathrm{var} / \mathrm{www} / \mathrm{cdrplive} /$ files $/$ provincial/79/HH\%20RAQ\%20v160923.pdf).

\section{Lameness Reduction Initiative Data}

Validation of the RAQ required the additional assessment of its objectivity and interobserver agreement between veterinarians trained to conduct the RAQ. After launching of the LRI in 2016, the RAQ was conducted by veterinarians after training through on-farm workshops. By the fall of 2018, 137 assessments were completed by 25 veterinarians. A user guide was provided for applicable questions to ensure further consistency (https://www.dairyresearch.ca/file.php?filename $=/$ var $/$ www $/$ cdrplive/files/provincial $/ 78 / \mathrm{HH} \% 20 \mathrm{RAQ}$ \%20User\%20Guide\%20v160923.pdf). Of the 65 herds enrolled in the study, 33 had also completed an RAQ with their veterinarian. Observer reliability was assessed through the comparison of scores of 33 herds between the veterinarians $(\mathrm{n}=14)$ and the graduate student (MV). Four of the 33 herds had completed 2 RAQ with their veterinarian; therefore, only the most recent was kept for comparison with the study RAQ.

\section{Lameness Assessment}

The entire lactating herd was videotaped while exiting the milking parlor after milking in the most suitable location with a flat surface and enough space to allow for a minimum of 4 strides. In some herds, slatted floors as well as floors that were more slippery than optimal were unavoidable. All lameness scoring was done by the same trained observer (MV) using the 5-point scale described in the Canadian Code of Practice for the Care and Handling of Dairy Cattle (National Farm Animal Care Council, 2009). Scores of 1 and 2 were considered nonlame, whereas scores of 3,4 , and 5 were recorded as lame. Prior to data collection, lameness assessment training was done using video footage from previous studies in Alberta and discussion with colleagues until agreement was met. However, interobserver agreement was not formally assessed. Selection of cows assessed for lameness depended on the number of videos in which cows were walking for at least 4 strides with nonobstructed views of the head, back, and feet simultaneously and had clearly visible identification linking to cow-level CanWest DHI information. Lameness scoring was then completed on all videos or systematically selected videos (e.g., every second or third), based on milking order, to yield at least 40 cows scored, which on average was $25 \%$ of the herd. The systematic selection was based on how many cows were eligible for scoring after videos were cleaned to ensure that the herd's final number of cows scored was spread evenly throughout the milking order. Assessment of intraobserver agreement for lame versus nonlame was done once all farm visits were complete by reanalyzing $10 \%$ of videos for $10 \%$ of participant herds, spread evenly from the first herd visited to the last and calculating the Kappa statistic. Intraobserver agreement for lame versus nonlame was high $(0.9 ; \mathrm{K} \geq 0.64)$. Additional cow-based measures, including parity, DIM, and daily milk production, were obtained from CanWest DHI (for the closest test date to date of study visit). 


\section{Lesion Data}

To account for a potential effect of seasonality on the presence of hoof lesions (Sanders et al., 2009), 1 yr of hoof trimming records was requested for each enrolled herd, retroactively from the date of the study visit in 2018 to the same date of 2017. For 2 enrolled herds that were interested in participation and actively contacted the graduate student (MV), the professional hoof trimmer did not use Hoof Supervisor (KS Dairy Consulting, Dresser, WI) and was not a member of WCCHTA. However, due to the trimmer's participation in the Alberta Dairy Hoof Health Project (Solano et al., 2016a), a study that collected data on hoof lesions based on the records of professional hoof trimmers (including most WCCHTA members), an exception was made. For these 2 herds, paper copies of trim records were collected and digitalized. Variables included in the requested trim data included trimmer, cow ID, trim date, lesions, claws, and treatment. Lesion severity was not recorded. Diagnosis and recording of lesions were consistent with ICAR classification (Egger-Danner et al., 2015) and analyzed by a previous study in Alberta (Solano et al., 2016a). Categorization of lesion types into infectious and noninfectious lesion outcomes was done whereby DD (all stages), interdigital dermatitis, foot rot, and heel erosion lesions were defined as infectious and white line lesion, sole ulcer, sole hemorrhage, toe ulcer, thin sole, white line hemorrhage, periopole ulcer, interdigital hyperplasia, horizontal fissure, vertical fissure, axial fissure, and corkscrew claw were defined as noninfectious.

\section{Data Management and Statistical Analysis}

To control for multiple records per cow, trim records were restricted to the 1 observation per unique cow closest to the study date visit. Because herd lesion prevalence in this study was calculated from multiple time points throughout the course of a year, unlike lameness prevalence, this outcome can be referred to as yearly lesion prevalence.

All statistical analyses were performed using Stata 15.1 (StataCorp, College Station, TX), and $P<0.05$ was considered significant. Herd-level characteristics were described using descriptive statistics to allow for comparison with provincial averages. Associations between herd lameness prevalence, yearly noninfectious lesion prevalence, and yearly infectious lesion prevalence and total RAQ score, noninfectious RAQ score, and infectious RAQ score, respectively, were estimated using Spearman's rank correlation. For analyses of infectious and noninfectious lesion cow-level outcomes, a partial trim was defined as $<80 \%$ of the herd being trimmed within a 15-d period, and a whole trim was defined as $\geq 80 \%$ of the herd being trimmed within a 15-d interval (Solano et al., 2016a).

If 2 independent variables were highly correlated ( $\mathrm{r}$ $\geq 0.60$ ), the variable with the strongest association with the outcome or the lowest number of missing observations was selected for analysis. First, univariable analyses were performed to assess associations between the cow-level outcome of interest, presence of lameness, noninfectious lesion, and infectious lesion and each independent variable. Variables with a crude association with $P \leq 0.25$ were included in multivariable analyses. Variables in multivariable analyses with $P<0.10$ were included for backward elimination, resulting in the final model where retained independent variables had an association with $P<0.05$. A confounding variable was retained if its removal resulted in a $\geq 30 \%$ change in the coefficient estimates of other significant predictors. Interaction was tested among significant predictors (2-way interactions). Farm was included as a random effect because of the significant variation in lameness and yearly lesion prevalence between herds. For lesion outcome analyses, hoof trimmer and trimming routine (partial or whole) were kept in the model as a fixed effect because of potential inconsistencies between trimmers and because partial-trim herds had higher prevalence estimates than whole-trim herds due to selection bias introduced by producers who select cows for trimming based on clinical signs.

For study herds that had also completed an RAQ with their veterinarian as part of Alberta Milk's LRI, median differences between the herds' study RAQ score and the veterinarian RAQ score were tested using the sign test. A $P$-value of $<0.05$ indicated that the median difference between scores is not equal to zero and there is a significant difference between study and veterinarian RAQ scores. In addition, Lin's concordance correlation coefficient, which reflects the level of agreement between 2 sets of test results (Dohoo et al., 2009), was calculated for comparison of the herds' study RAQ score and the veterinarian RAQ score, with a coefficient of $\geq 0.60$ being arbitrarily defined as a good agreement.

\section{Study 2}

For our third objective (study 2), data used were previously collected from 10 herds between November 2013 and June 2014 for a study designed for the validation of the M-stage scoring system for DD lesions, where farm and cow selection were described (Solano et al., 2017). Participating herds were visited twice, except for 2 herds that contributed data from 1 visit only. All cows within the herd were videotaped and locomotion 
was scored by 1 trained observer, and a cow was determined to be lame if a limp consistent with a score $\geq 3$ on the 5-point scale described above was observed. A WCCHTA hoof trimmer visited the herd within 12 to $48 \mathrm{~h}$ after locomotion scoring to treat and record lesions using Hoof Supervisor software (KS Dairy Consulting). One herd was visited by the hoof trimmer $3 \mathrm{~d}$ after locomotion scoring due to a snow storm in the days before. Lesion and treatment data were digitally collected from the hoof trimmers. To determine the cow-level association between presence of a lesion and lameness, crude odds ratios were calculated for the most common lesions and collectively as infectious and noninfectious lesion categories.

\section{RESULTS}

\section{Study 1}

Study farms had a mean herd size of 163 lactating cows, with mean daily and 305-d milk production of 36.9 and $11,085 \mathrm{~kg}$, respectively (Table 1). Herd characteristics of this study represented the overall population of cows housed in freestalls in Alberta, with herd size and milk production being slightly higher due to exclusion of small herds.

A total of 3,759 cows were assessed for lameness. On average, $41 \%(17-78 \%)$ of the lactating herd was assessed for lameness. Herd-level lameness prevalence ranged from 2 to $56 \%$, with a median of $19.5 \%$ on the 65 farms (Figure 1$)$. The $10 \%$ of herds $(n=6)$ with the lowest lameness prevalence had a prevalence of $<8 \%$, whereas in the $10 \%$ of herds with the highest lameness prevalence, $>38 \%$ of the cows were lame.

For the 63 herds with accessible trim records, a total of 22,670 cow records were collected from the 8 hoof trimmers. Trim records were inaccessible for 2 herds; one trimmer experienced a hard drive malfunction, and both of these herds were unable to find the trim records that the trimmer would have given them after trim sessions. After restricting observations to the 1 most recent trim record per unique cow, 13,530 records were available for analysis, and 13,530 was therefore the de- nominator value for yearly prevalence calculations. Of these records, $29.5 \%$ of cows had at least 1 hoof lesion, and $9 \%$ of those cows had $>1$ hoof lesion (Table 2). Overall, herd-level yearly infectious lesion prevalence, making up $9.1 \%$ of $\mathrm{DD}$, ranged from 0 to $49 \%$ with a median of $9.6 \%$, and yearly noninfectious lesion prevalence ranged from 2 to $39 \%$ with a median of $14.7 \%$. Most common noninfectious lesions were white line, sole ulcer, and sole hemorrhage, with medians of 5.5, 4.9 , and $2.2 \%$, respectively. Mean estimates differed between partial-trim herds (18.1\%; 95\% CI: 15.1-21.1) and whole-trim herds $(12.9 \%$; 95\% CI: 10.8-15.0) for yearly noninfectious lesion prevalence, with a mean difference of $5.2 \%$ (95\% CI: 1.6-8.9; Table 2).

Total RAQ score ranged from 50 to 114 points with a mean of $81( \pm 15)$ points out of a maximum of 241 points for 65 herds. Infectious RAQ score ranged from 27 to 64 points out of a maximum of 124 points with a mean of $44( \pm 8)$ points, and noninfectious RAQ score ranged from 19 to 62 points out of a maximum of 117 points with a mean of $37( \pm 9)$ points for 63 herds.

Within-herd lameness prevalence and total RAQ score $(\mathrm{r}=0.26, P<0.05)$ and within-herd yearly noninfectious lesion prevalence and noninfectious RAQ score $(\mathrm{r}=0.45, P<0.001)$ were positively associated. However, there was no association between within-herd yearly infectious lesion prevalence and infectious RAQ score $(\mathrm{r}=0.15, P=0.25)$.

Multilevel Logistic Models. Cow-level variables were only applicable in the final model with lame as the outcome. There were no confounding variables or significant 2-way interactions in any model. In the final model analyses, total RAQ score, infectious RAQ score, and noninfectious RAQ score had no evidence of an association with the odds of a cow being lame, having an infectious lesion, and having a noninfectious lesion, respectively. The odds of a cow being lame increased with increasing parity, with cows in third and fourth or higher lactation being 4 and 7 times more often lame, respectively, compared with first-lactation cows (Table 3 ). Cows in a herd with $>165$ lactating cows were twice more likely to have an infectious lesion compared with cows in herds with $<110$ cows (Table 4 ). In herds that

Table 1. Descriptive characteristics (mean $\pm \mathrm{SD}$ ) of 65 study dairy farms and the average freestall dairy farm in Alberta, Canada

\begin{tabular}{lcc}
\hline Variable & Average freestall farm & Study farms \\
\hline Herd size (no. of lactating cows) & 140 & $163 \pm 77$ \\
Daily milk yield (kg) & 35.2 & $36.9 \pm 3.6$ \\
Parity & 2.2 & $2.2 \pm 0.2$ \\
305-d milk yield (kg) & 10,643 & $11,085 \pm 899$ \\
DIM & 172 & $170 \pm 20$ \\
\hline
\end{tabular}

${ }^{1}$ Data from 2018. Source: CanWest DHI (Guelph, ON, Canada). 


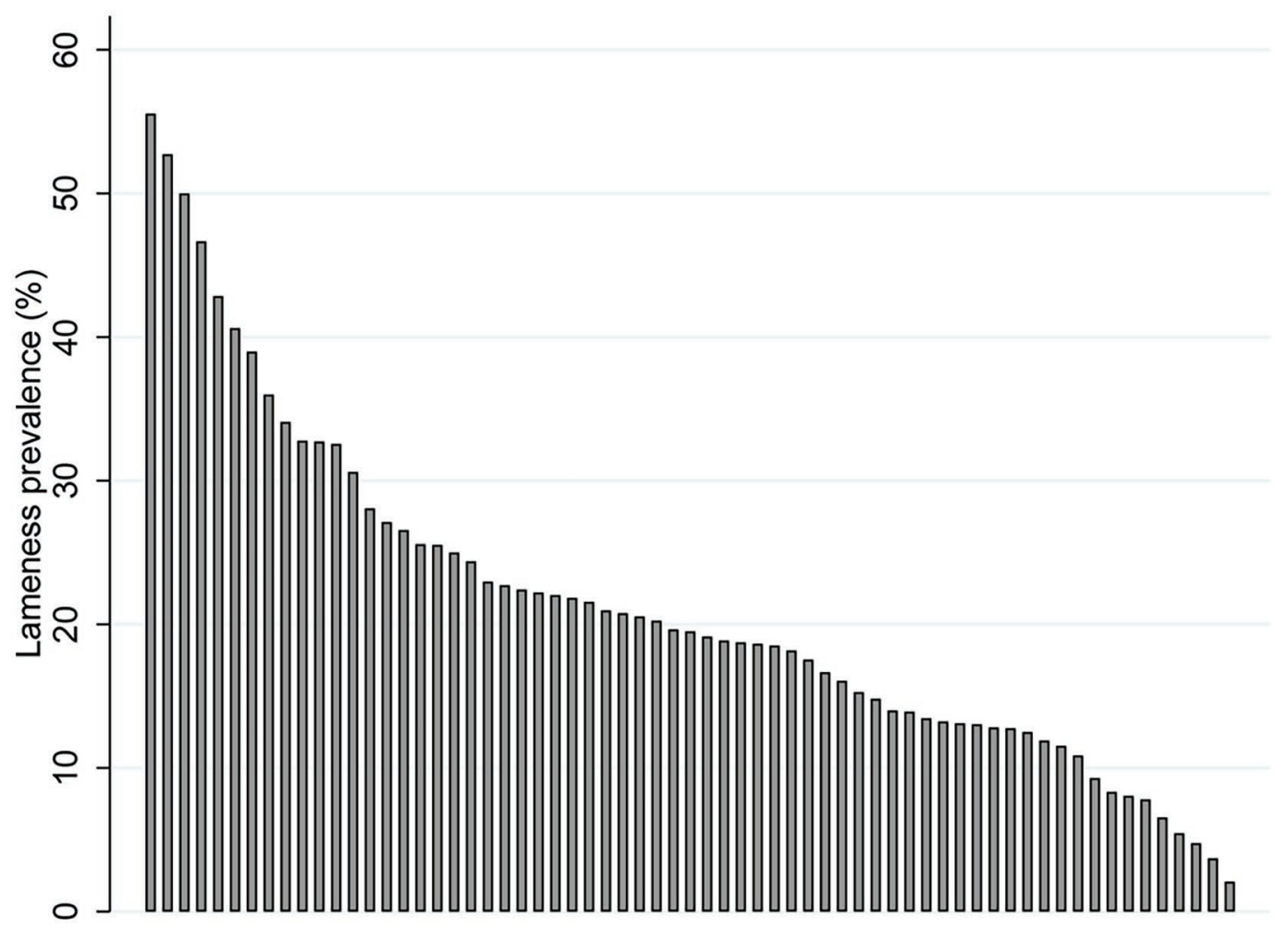

Figure 1. Distribution of within-herd lameness prevalence for 65 dairy herds in Alberta, Canada. Each bar represents a herd.

were milked 3 times a day, cows were $37 \%$ less likely to have a noninfectious lesion than cows in herds milking 2 times a day (Table 5). The odds of a noninfectious lesion were $33 \%$ less in herds with a whole-herd trimming routine than in herds with a partial-herd trimming routine.

Interrater Agreement. Median total, infectious, and noninfectious RAQ scores were not significantly different between veterinarian-administered assessments and assessments by the graduate student (MV) in this study (Table 6). Additionally, concordance coefficients, which reflect the level of agreement between veterinarian and graduate student assessment scores, were $0.71,0.58$, and 0.71 for total RAQ score, infectious RAQ score, and noninfectious RAQ score, respectively.

\section{Study 2}

A total of 1,680 cow records were collected from the herds' hoof trimmers $(\mathrm{n}=2)$ and were reduced to 1,581 records when including cows with complete lameness observations. Distribution of lesion types and their association with lameness are summarized in Table 7 . Overall, $93 \%$ of lame cows had the presence of a lesion

Table 2. Cow-level prevalence (\%) and median (minimum to maximum in parentheses) within-herd prevalence (\%) of hoof lesions in 63 herds and 13,530 dairy cows as recorded by 8 trimmers in Alberta, Canada

\begin{tabular}{|c|c|c|c|c|c|c|}
\hline \multirow[b]{2}{*}{ Lesion } & \multicolumn{2}{|c|}{ Partial trim $(\mathrm{n}=32)$} & \multicolumn{2}{|c|}{ Whole trim $(\mathrm{n}=31)$} & \multicolumn{2}{|c|}{ Overall $(\mathrm{n}=63)$} \\
\hline & Cow & Herd & Cow & Herd & Cow & Herd \\
\hline Multiple lesions & 10.3 & $8.6(0.0-30.1)$ & 8.1 & $5.7(1.0-19.6)$ & 9.3 & $8.3(0.0-30.1)$ \\
\hline Infectious & 15.6 & $10.5(0.0-49.0)$ & 14.5 & $7.7(0.0-47.7)$ & 15.1 & $9.6(0.0-49.0)$ \\
\hline Digital dermatitis & 14.6 & $10.1(0.0-49.0)$ & 13.6 & $7.5(0.0-43.3)$ & 14.1 & $9.1(0.0-49.0)$ \\
\hline Noninfectious & 18.3 & $17.0(2.6-38.8)$ & 12.4 & $11.7(2.4-25.6)$ & 15.4 & $14.7(2.4-38.8)$ \\
\hline Sole hemorrhage & 3.0 & $1.5(0.0-12.3)$ & 3.5 & $2.6(0.0-14.9)$ & 3.2 & $2.3(0.0-14.9)$ \\
\hline
\end{tabular}


Table 3. Final mixed-effects logistic regression model for lameness with cow- and herd-level factors for 65 dairy herds in Alberta, Canada $(\mathrm{n}=3,641)$

\begin{tabular}{lcccr}
\hline Variable & Coefficient & Odds ratio & $95 \% \mathrm{CI}$ & $P$-value \\
\hline Total RAQ ${ }^{1}$ score & 0.01 & 1.01 & $1.00-1.02$ & 0.107 \\
DIM & 0.00 & 1.00 & $1.00-1.00$ & 0.011 \\
Parity & & & & \\
1 & Referent & & & \\
2 & 0.43 & 1.54 & $1.20-1.98$ & 0.001 \\
3 & 1.41 & 4.08 & $3.16-5.27$ & $<0.001$ \\
$\geq 4$ & 1.98 & 7.24 & $5.64-9.28$ & $<0.001$ \\
Herd-average DIM & 0.01 & 1.01 & $1.00-1.02$ & 0.005 \\
\hline
\end{tabular}

${ }^{1}$ Risk assessment questionnaire.

Table 4. Final mixed-effects logistic regression model for infectious lesions with herd-level factors for 63 dairy herds in Alberta, Canada $(\mathrm{n}=13,530)$

\begin{tabular}{lcccr}
\hline Variable & Coefficient & Odds ratio & $95 \% \mathrm{CI}$ & $P$-value \\
\hline Infectious RAQ $^{1}$ score & 0.01 & 1.01 & $0.98-1.05$ & 0.485 \\
Herd-average DIM $^{\text {Herd size }}$ & 0.03 & 1.03 & $1.01-1.04$ & $<0.001$ \\
$<110$ & & & & \\
$110-164$ & Referent & & & \\
$\geq 165$ & 0.57 & 1.76 & $0.88-3.50$ & 0.107 \\
& 0.80 & 2.21 & $1.02-4.80$ & 0.044 \\
\hline
\end{tabular}

${ }^{1}$ Risk assessment questionnaire.

${ }^{2}$ Number of lactating cows.

Table 5. Final mixed-effects logistic regression model for noninfectious lesions with herd-level factors for 63 dairy herds in Alberta, Canada $(\mathrm{n}=13,530)$

\begin{tabular}{lcccc}
\hline Variable & Coefficient & Odds ratio & $95 \%$ CI & $P$-value \\
\hline $\begin{array}{l}\text { Noninfectious RAQ score } \\
\text { Milking frequency }\end{array}$ & 0.02 & 1.02 & $1.00-1.03$ & 0.027 \\
2 times/d & Referent & & & \\
3 times/d & -0.46 & 0.63 & $0.47-0.84$ & 0.002 \\
$\begin{array}{l}\text { Trimming routine } \\
\text { Partial }\end{array}$ & $\begin{array}{c}\text { Referent } \\
\text { Whole }\end{array}$ & & & \\
\hline
\end{tabular}

${ }^{1}$ Risk assessment questionnaire.

${ }^{2}$ Partial: $<80 \%$ of lactating and dry cows trimmed within a 15 -d interval; whole: $\geq 80 \%$ of lactating and dry cows trimmed within a 15 -d interval.

Table 6. Score comparison and agreement between the graduate student and veterinarians who completed a risk assessment questionnaire (RAQ) on 33 study participant farms

\begin{tabular}{|c|c|c|c|c|c|}
\hline Scores & Study $^{1}$ & Veterinarian $^{1}$ & $\begin{array}{c}\text { Score } \\
\text { differential }^{1}\end{array}$ & $\begin{array}{l}\text { Sign test } \\
P \text {-value }\end{array}$ & $\begin{array}{c}\text { Concordance } \\
\text { correlation coefficient }\end{array}$ \\
\hline Total RAQ & $81(56-112)$ & $80(53-126)$ & $8(0-26)$ & 0.281 & 0.705 \\
\hline Infectious RAQ & $43(27-56)$ & $45(24-68)$ & $5(0-20)$ & 0.215 & 0.582 \\
\hline Section 2 & $12(6-18)$ & $12(4-19)$ & $3(0-6)$ & 0.210 & 0.743 \\
\hline Section 4 & $3(0-16)$ & $5(0-13)$ & $2(0-9)$ & 0.136 & 0.495 \\
\hline Section 5 & $9(2-22)$ & $11(0-21)$ & $3(0-12)$ & 0.856 & 0.647 \\
\hline Section 6 & $5(0-19)$ & $5(1-23)$ & $3(0-18)$ & 0.362 & 0.424 \\
\hline Section 9 & $12(6-19)$ & $11(7-29)$ & $2(0-11)$ & 0.572 & 0.465 \\
\hline
\end{tabular}

\footnotetext{
${ }^{1}$ Values are median (minimum and maximum in parentheses).
} 
Table 7. Distribution and association between lesion and lameness cases as recorded for 1,581 dairy cows on 10 farms in Alberta, Canada

\begin{tabular}{|c|c|c|c|c|c|}
\hline \multirow[b]{2}{*}{ Lesion type } & \multicolumn{2}{|c|}{$\begin{array}{l}\text { Lameness } \\
\text { (no. of cows) }\end{array}$} & \multirow[b]{2}{*}{ Lame (\%) } & \multirow{2}{*}{$\begin{array}{l}\text { Lameness cases } \\
(\% ; \mathrm{n}=303)\end{array}$} & \multirow{2}{*}{$\begin{array}{l}\text { Odds of lameness } \\
\quad(95 \% \mathrm{CI})\end{array}$} \\
\hline & Absent & Present & & & \\
\hline Infectious lesion & 1,018 & 260 & 20.3 & 85.8 & $1.5(1.1-2.2)$ \\
\hline Digital dermatitis & 912 & 245 & 21.2 & 80.9 & $1.7(1.2-2.3)$ \\
\hline Noninfectious lesion & 433 & 186 & 30.0 & 61.4 & $3.1(2.4-4.0)$ \\
\hline
\end{tabular}

and $21 \%$ of cows with a lesion were lame. Noninfectious lesions had higher odds of lameness than infectious lesions, whereby cows with a noninfectious lesion were 3.1 (2.4-4.0) times more likely to be lame compared with cows with $\mathrm{DD}$, the most common infectious lesion, with an odds ratio of 1.7 (1.2-2.3). Though there were fewer cases of sole ulcer and white line, the cows that presented these lesions had $5.7(3.6-8.9)$ and 6.3 (3.6-11.3) times the odds of being lame, respectively.

\section{DISCUSSION}

The 65 freestall herds included in study 1 had a lameness prevalence of $20 \%$ (95\% CI: 18.4-24.3), consistent with reported estimates of $21 \%$ in the Maritime provinces of Canada (Jewell et al., 2019) and 19\% last reported in Alberta (Solano et al., 2015). The latter comparison could be reflective of the continuing lack of prevention and control strategy uptake by producers in the province. Although the producers make the final decision on implemented changes, this result may also be indicative of insufficient support from their team of advisors and other personnel in the dairy industry that could play a more important role in uptake of lameness prevention. Our study estimate was higher than the 10\% reported among 17 US states (Adams et al., 2017), $15 \%$ in Canada and Michigan (Westin et al., 2016), and $13 \%$ in Wisconsin (Cook et al., 2016). Lameness prevalence in this study was lower than 28, 31, and $55 \%$ in British Columbia, California, and the northeastern United States, respectively (von Keyserlingk et al., 2012).

Differences in lameness prevalence can be due to housing systems, dairy characteristics, and methodology for locomotion scoring and lameness case definition. The study including 17 US states (Adams et al., 2017) comprising herds with varying housing types, of which $32 \%$ combined had tiestall, pasture, and open lot systems, which can have a positive effect on lameness compared with freestall systems. Herd size has also been reported to have a negative association with prevalence
(Chapinal et al., 2014a; Solano et al., 2015), with larger herds having lower prevalence, perhaps because large operations have more staff to monitor, prevent, and control lameness and lesions. This can support the low prevalence estimate reported in Wisconsin as well as their selection for high-performance herds that could be less likely to have a lameness problem due to its negative association with milk production at the cow level (Reader et al., 2011), which could collectively apply to the herd level. Milking system can also be a factor in lameness prevalence, in which the lower estimate in Canada and Michigan could be attributable to herds having automated milking systems, which may relate to the common producer perception of having more time to observe and detect lameness (Tse et al., 2017). However, more research is required on lameness prevalence in automated milking systems, as another study had a larger estimate of $26 \%$ (King et al., 2016). The selection of cows for assessment can also affect lameness prevalence. In British Columbia, California, and the northeastern United States, high production groups were selected for assessment because they are most susceptible to lameness (Green et al., 2002). In study 1, production and stage of lactation were not cow selection criteria and did not have an association with lameness, nor was the significance of average herd DIM, measured on a continuous scale, relevant with odds ratio $=1$. Additionally, it is well recognized that gait scoring methods used among studies are subjective; therefore, the validity of the scoring system by determining observer agreement is important for valid comparison between studies.

Yearly lesion prevalence estimates reported in this study were comparable with a prior study in Alberta (Solano et al., 2016a). After using the same methods to define herd trimming routine, it is of most interest to compare estimates for whole-trim herds, as they are most representative of lesion prevalence rather than partial-trim herds due to selection bias introduced by the producer leading to overestimation of prevalence. Yearly prevalence of infectious lesions was consistent, 
with $16 \%$ previously reported (Solano et al., 2016a), whereas yearly prevalence of noninfectious lesions decreased from 16 to $12 \%$, although the statistical significance of this decline was undetermined. Methodology was very similar between these 2 studies, with consistency in participant trimmers who diagnosed and recorded lesions using the same software. Therefore, yearly lesion prevalence has remained relatively unchanged in Alberta after 6 yr between data collection.

In study 2 , lesions were reported in $93 \%$ of lame cows, consistent with previous studies (Murray et al., 1996; Somers and O'Grady, 2015). However, it is equally important to note that only $21 \%$ of cows presenting a lesion were lame. Sole ulcer and white line lesion had the highest association with lameness, where 54 and $58 \%$ of cows affected were lame, respectively. These results were consistent with the $54 \%$ (sole ulcer) and $61 \%$ (white line) reported in a recent Malaysian study (Sadiq et al., 2017). Although DD was the most prevalent foot lesion, only $20 \%$ of cows affected with this lesion were lame. A plausible reason could be that certain stages of DD, such as the active M2 stage, are more painful than other more advanced (or chronic) stages that have a higher likelihood of causing clinical signs of lameness (Plummer and Krull, 2017). Another study reported pain thresholds to be significantly different among active, healing, and healed lesions, with active lesions being the most painful (Cutler et al., 2013). These reports, including that of the second study, suggest that examining only lame cows to determine the prevalence of hoof lesions will result in an underestimation, especially for $\mathrm{DD}$, as cows with a lesion that does not result in lameness will be missed. However, due to the subjective nature of lameness assessment that is based on only 1 observation, there is always the possibility of a lame cow being misclassified as nonlame (Eriksson et al., 2020). Regular hoof inspection as well as more frequent lameness scoring of the herd would therefore be beneficial for early identification of lesions before altering a cow's gait to prevent chronic cases. Additionally, herds with milking parlors can routinely monitor for DD lesions during milking for early identification and treatment of these lesions specifically.

Although total RAQ score and within-herd lameness prevalence, as well as noninfectious RAQ score and within-herd yearly noninfectious lesion prevalence, were associated, these associations were relatively weak. This could be the result of an inaccuracy of the RAQ in identifying risk factors for lameness, highlighting the need of improvement in strengthening associations between risk factors and lameness and lesion prevalence or indicating the potential of important risk factors not being captured in the RAQ. Conversely, there may be risk factors presented in the RAQ that have little to no effect on a cow becoming or staying lame. The important question remains of which herd-level risk factors may have more of an effect on lameness than others, to then be followed by adjustment of the weights of the risk factor scores based on the answer to this question. This could include the importance of risk factor exposure during the first pregnancy, lactation, and dry periods of a cow's life in prevention of lameness. A follow-up longitudinal study is necessary for increased understanding through risk quantification and determining which control and prevention strategies should be prioritized by producers for an increased success rate of lameness mitigation in their herds.

Unlike previous studies (Solano et al., 2015; Adams et al., 2017), herd size was not a risk factor for lameness in study 1. A possible reason could be the different distribution of herd size among participants enrolled in these studies that resulted in an association with lameness prevalence. In the United States, there is a much wider range in herd size, which the Adams et al. (2017) study reflected with their definitions of medium (100-499 cows) and large ( $\geq 500$ cows) herds. In contrast, the Canadian study included herds in Ontario and Quebec, in addition to Alberta, where average herd sizes are smaller and thus overall had more small herd participants than in study 1 . A cow in a herd with $\geq 165$ lactating cows, however, did have 2 times the odds of having an infectious lesion compared with a cow in a herd of $<100$ cows. This association could be due to larger herds having an increased likelihood of being open herds, in which the purchase of animals from elsewhere comes with increased risk of introducing infectious lesions (Oliveira et al., 2017). The weak association between prevalence of infectious lesions and lameness in study 2 could explain why herd size is a risk factor for infectious lesions and not lameness.

In study 1, milking 3 times a day had a protective effect against noninfectious lesions compared with milking 2 times a day. This result is surprising and contrasts the results of a previous study that determined lameness prevalence to be positively associated with time spent milking (Espejo and Endres, 2007). Their result would be expected given the additional standing time in the holding pen that would exert more pressure on the claw; however, this could be counteracted by milking fewer cows in several groups. Perhaps for the herds in study 1 , the additional milking time may also allow for increased monitoring and detection of problem cows with noninfectious lesions that may be presenting signs of lameness. Few studies have investigated the effect of 
milking frequency on hoof health, and more research would be beneficial in better understanding this association.

In study 1 , herds with a trimming routine in which the whole herd is trimmed within $15 \mathrm{~d}, 2$ or 3 times a year, had a lower yearly prevalence of noninfectious lesions. This was also reflected by the significant difference in estimates between partial-trim and whole-trim herds for noninfectious lesions only. Selection bias in partial-trim herds can explain these results, whereby producers select a proportion of cows to present to the trimmer, including problem cows that are visibly lame, causing an overestimation of prevalence (Solano et al., 2016a). The stronger association between noninfectious lesions and lameness reported in study 2 may explain why trimming routine had an effect on these lesions and not infectious lesions. Additionally, infectious lesions can be treated by farm staff with more ease than the corrective trimming required for treatment of noninfectious lesions. However, trimming routine was not a significant variable when tested in the logistic regression models for lameness in study 1, perhaps due to a lack of statistical power. The study was not designed to analyze the effect of trimming routine on prevalence, but trimming routine was included in the model to identify potential variation caused by this variable.

In the RAQ validation of interrater agreement, there was no significant difference in scores for the 33 herds that had completed an RAQ by both their herd veterinarian and lead researcher of this study except for a weaker agreement for infectious RAQ score. This could be explained by more subjective questions identifying risk for infectious lesions, such as bedding wetness and leg cleanliness, that can be further affected by weather at the time of assessment for outside pregnant heifer and dry cow facilities. Question content and score weights of the risk factors, rather than inconsistency between evaluators, are more likely to explain the inaccuracy of the RAQ in reflecting lameness and lesion prevalence in the herd and thus require further research.

Our cross-sectional study design for study 1 allows for the possibility of biased associations between RAQ scores and prevalence of lesions and lameness. This could happen if participant herds made changes to their management or facility design shortly before the date of the study visit, resulting in a prevalence estimate that had yet to be affected by the change. Management questions in the RAQ relied on the responses of the producers whereby a nonrepresentative answer may have resulted in an inaccurate overall score. Another limitation of study 1 was the methods used to calculate our herd lesion prevalence estimates that also may have affected their association with RAQ scores. Without having trimming data of the whole herd for participants near the time of the study visit, our definition of lesion prevalence using 1 observation per cow presented to the hoof trimmer within a year, retrospective from the time of visit, limits the representativity of prevalence estimates when evaluating their association with RAQ scores. For this reason, weak associations between RAQ scores and lesion prevalence may be due to the methods used to measure the latter. Prevalence is a measure of both duration and incidence of a disease. Therefore, when measuring lesion prevalence in a cross-sectional study design, it is also important to consider that some lesions can have a short duration, which may lead to an underestimation of prevalence, and some can have a longer duration, which may lead to an overestimation of prevalence. Reliable recording of all new cases of lesions by both the producer and hoof trimmer will allow for an accurate measure of incidence. Although the study presents these limitations for lesion prevalence, chronicity of lesions and accurate recording of new cases are already complex factors that make it difficult to achieve true prevalence regardless of the methods used.

\section{CONCLUSIONS}

Lameness prevalence remains 20\% in Alberta freestall herds and has not changed since the last study in 2012 . The associations between RAQ scores and herd lameness and yearly lesion prevalence were nonexistent or weak. There was no difference in scores between observers, which indicates reliability of the RAQ, but improvement of the associations between lameness and lesion prevalence and RAQ scores requires further research in identifying risk factors within the questionnaire, followed by adjustment of question content and risk score weights. This will result in an RAQ that more accurately identifies risk for lameness and lesions in the herd and that allows for a clearer approach to prevention and control strategies. The RAQ is still viewed as a helpful and practical approach in the facilitation of discussion between producers and their advisors on lameness reduction and control in their herds.

\section{ACKNOWLEDGMENTS}

The authors thank the dairy producers and Western Canadian Certified Hoof Trimmers Association hoof trimmers in Alberta for their participation in this study. We also appreciate Makaela Douglas (University of Calgary, AB, Canada) and Laura Solano (Farm Animal Care Associates, AB, Canada) for their contribution to data collection and John Kastelic (University of Calgary) for editing this manuscript. This study was 
funded by the Industry Market and Development Fund (Edmonton, AB, Canada) and Alberta Milk (Edmonton, AB, Canada). The authors have no conflicts of interest.

\section{REFERENCES}

Adams, A. E., J. E. Lombard, C. P. Fossler, I. N. Roman-Muniz, and C. A. Kopral. 2017. Associations between housing and management practices and the prevalence of lameness, hock lesions, and thin cows on US dairy operations. J. Dairy Sci. 100:2119-2136. https://doi.org/10.3168/jds.2016-11517.

Alberta Milk. 2016. Lameness Reduction Initiative. Edmonton, AB Canada. Accessed Oct. 21, 2019. https://www.dairyresearch.ca/ file.php?filename $=/ \mathrm{var} / \mathrm{www} / \mathrm{cdrplive} /$ files $/$ provincial $/ 79 / \mathrm{HH}$ \%20RAQ\%20v160923.pdf.

Barker, Z. E., K. A. Leach, H. R. Whay, N. J. Bell, and D. C. Main. 2010. Assessment of lameness prevalence and associated risk factors in dairy herds in England and Wales. J. Dairy Sci. 93:932-941. https://doi.org/10.3168/jds.2009-2309.

Bell, N. J., M. J. Bell, T. G. Knowles, H. R. Whay, D. J. Main, and A. J. Webster. 2009. The development, implementation and testing of a lameness control programme based on HACCP principles and designed for heifers on dairy farms. Vet. J. 180:178-188. https:// doi.org/10.1016/j.tvjl.2008.05.020.

Booth, C. J., L. D. Warnick, Y. T. Grohn, D. O. Maizon, C. L. Guard, and D. Janssen. 2004. Effect of lameness on culling in dairy cows. J. Dairy Sci. 87:4115-4122. https://doi.org/10.3168/jds.S0022 -0302(04)73554-7.

Chapinal, N., Y. Liang, D. M. Weary, Y. Wang, and M. A. von Keyserlingk. 2014a. Risk factors for lameness and hock injuries in Holstein herds in China. J. Dairy Sci. 97:4309-4316. https://doi.org/ 10.3168/jds.2014-8089.

Chapinal, N., M. A. von Keyserlingk, R. L. Cerri, K. Ito, S. J. Leblanc, and D. M. Weary. 2013. Short communication: Herd-level reproductive performance and its relationship with lameness and leg injuries in freestall dairy herds in the northeastern United States. J. Dairy Sci. 96:7066-7072. https://doi.org/10.3168/jds.2013-6967.

Chapinal, N., D. M. Weary, L. Collings, and M. A. von Keyserlingk. 2014b. Lameness and hock injuries improve on farms participating in an assessment program. Vet. J. 202:646-648. https://doi.org/10 $.1016 / j . t v j 1.2014 .09 .018$.

Cook, N. B. 2017. A review of the design and management of footbaths for dairy cattle. Vet. Clin. North Am. Food Anim. Pract. 33:195-225. https://doi.org/10.1016/j.cvfa.2017.02.004.

Cook, N. B., J. P. Hess, M. R. Foy, T. B. Bennett, and R. L. Brotzman. 2016. Management characteristics, lameness, and body injuries of dairy cattle housed in high-performance dairy herds in Wisconsin. J. Dairy Sci. 99:5879-5891. https://doi.org/10.3168/jds.2016 $-10956$.

Cutler, J. H., G. Cramer, J. J. Walter, S. T. Millman, and D. F. Kelton. 2013. Randomized clinical trial of tetracycline hydrochloride bandage and paste treatments for resolution of lesions and pain associated with digital dermatitis in dairy cattle. J. Dairy Sci. 96:7550-7557. https://doi.org/10.3168/jds.2012-6384.

Cutler, J. H. H., J. Rushen, A. M. de Passille, J. Gibbons, K. Orsel, E. Pajor, H. W. Barkema, L. Solano, D. Pellerin, D. Haley, and E. Vasseur. 2017. Producer estimates of prevalence and perceived importance of lameness in dairy herds with tiestalls, freestalls, and automated milking systems. J. Dairy Sci. 100:9871-9880. https:// doi.org/10.3168/jds.2017-13008.

Dohoo, I., W. Martin, and H. Stryhn. 2009. Veterinary Epidemiologic Research. 2nd ed. VER Inc., Charlottetown, PE, Canada.

Egger-Danner, C., P. Nielsen, A. Fiedler, K. Müller, T. Fjeldaas, D. Döpfer, V. Daniel, C. Bergsten, G. Cramer, A.-M. Christen, K. F. Stock, G. Thomas, M. Holzhauer, A. Steiner, J. Clarke, N. Capion, N. Charfeddine, J. E. Pryce, E. Oakes, J. Burgstaller, B. Heringstad, C. Ødegård, and J. Kofler. 2015. ICAR Claw Health
Atlas. Accessed Sep. 7, 2020. http://www.icar.org/Documents/ ICAR_Claw_Health_Atlas.pdf.

Eriksson, H. K., R. R. Daros, M. A. G. von Keyserlingk, and D. M. Weary. 2020. Effects of case definition and assessment frequency on lameness incidence estimates. J. Dairy Sci. 103:638-648. https: //doi.org/10.3168/jds.2019-16426.

Espejo, L. A., and M. I. Endres. 2007. Herd-level risk factors for lameness in high-producing Holstein cows housed in freestall barns. J. Dairy Sci. 90:306-314. https://doi.org/10.3168/jds.S0022 $-0302(07) 72631-0$.

Green, L. E., V. J. Hedges, Y. H. Schukken, R. W. Blowey, and A. J. Packington. 2002. The impact of clinical lameness on the milk yield of dairy cows. J. Dairy Sci. 85:2250-2256. https://doi.org/10 .3168/jds.S0022-0302(02)74304-X.

Jewell, M. T., M. Cameron, J. Spears, S. L. McKenna, M. S. Cockram, J. Sanchez, and G. P. Keefe. 2019. Prevalence of lameness and associated risk factors on dairy farms in the Maritime Provinces of Canada. J. Dairy Sci. 102:3392-3405. https://doi.org/10.3168/jds .2018-15349.

King, M. T. M., E. A. Pajor, S. J. LeBlanc, and T. J. DeVries. 2016. Associations of herd-level housing, management, and lameness prevalence with productivity and cow behavior in herds with automated milking systems. J. Dairy Sci. 99:9069-9079. https://doi .org/10.3168/jds.2016-11329.

Leach, K. A., H. R. Whay, C. M. Maggs, Z. E. Barker, E. S. Paul, A. K. Bell, and D. C. Main. 2010. Working towards a reduction in cattle lameness: 1 . Understanding barriers to lameness control on dairy farms. Res. Vet. Sci. 89:311-317. https://doi.org/10.1016/j .rvsc. 2010.02.014.

Machado, V. S., L. S. Caixeta, J. A. McArt, and R. C. Bicalho. 2010. The effect of claw horn disruption lesions and body condition score at dry-off on survivability, reproductive performance, and milk production in the subsequent lactation. J. Dairy Sci. 93:4071-4078. https://doi.org/10.3168/jds.2010-3177.

Main, D. C., K. A. Leach, Z. E. Barker, A. K. Sedgwick, C. M. Maggs, N. J. Bell, and H. R. Whay. 2012. Evaluating an intervention to reduce lameness in dairy cattle. J. Dairy Sci. 95:2946-2954. https: //doi.org/10.3168/jds.2011-4678.

Morabito, E., H. W. Barkema, E. A. Pajor, L. Solano, D. Pellerin, and K. Orsel. 2017. Effects of changing freestall area on lameness, lying time, and leg injuries on dairy farms in Alberta, Canada. J. Dairy Sci. 100:6516-6526. https://doi.org/10.3168/jds.2016-12467.

Murray, R. D., D. Y. Downham, M. J. Clarkson, W. B. Faull, J. W. Hughes, F. J. Manson, J. B. Merritt, W. B. Russell, J. E. Sutherst, and W. R. Ward. 1996. Epidemiology of lameness in dairy cattle: Description and analysis of foot lesions. Vet. Rec. 138:586-591. https://doi.org/10.1136/vr.138.24.586.

National Farm Animal Care Council. 2009. Canadian code of practice for the care and handling of dairy cattle. Ottawa, ON, Canada Accessed Oct. 2, 2019. https://www.nfacc.ca/pdfs/codes/dairy _code_of_practice.pdf.

Oliveira, V. H. S., J. T. Sorensen, and P. T. Thomsen. 2017. Associations between biosecurity practices and bovine digital dermatitis in Danish dairy herds. J. Dairy Sci. 100:8398-8408. https://doi.org/ 10.3168/jds.2017-12815.

Plummer, P. J., and A. Krull. 2017. Clinical perspectives of digital dermatitis in dairy and beef cattle. Vet. Clin. North Am. Food Anim. Pract. 33:165-181. https://doi.org/10.1016/j.cvfa.2017.02.002.

Reader, J. D., M. J. Green, J. Kaler, S. A. Mason, and L. E. Green. 2011. Effect of mobility score on milk yield and activity in dairy cattle. J. Dairy Sci. 94:5045-5052. https://doi.org/10.3168/jds .2011-4415.

Relun, A., A. Lehebel, M. Bruggink, N. Bareille, and R. Guatteo. 2013. Estimation of the relative impact of treatment and herd management practices on prevention of digital dermatitis in French dairy herds. Prev. Vet. Med. 110:558-562. https://doi.org/10.1016/j .prevetmed.2012.12.015.

Sadiq. M. B., S. Z. Ramanoon, R. Mansor, S. S. Syed-Hussain, and W. M. Shaik Mossadeq. 2017. Prevalence of lameness, claw lesions, and associated risk factors in dairy farms in Selangor, Malaysia. 
Trop. Anim. Health Prod. 49:1741-1748. https://doi.org/10.1007/ s11250-017-1387-4.

Sanders, A. H., J. K. Shearer, and A. De Vries. 2009. Seasonal incidence of lameness and risk factors associated with thin soles, white line disease, ulcers, and sole punctures in dairy cattle. J. Dairy Sci. 92:3165-3174. https://doi.org/10.3168/jds.2008-1799.

Solano, L., H. W. Barkema, C. Jacobs, and K. Orsel. 2017. Validation of the M-stage scoring system for digital dermatitis on dairy cows in the milking parlor. J. Dairy Sci. 100:1592-1603. https:// doi.org/10.3168/jds.2016-11365.

Solano, L., H. W. Barkema, S. Mason, E. A. Pajor, S. J. LeBlanc, and K. Orsel. 2016a. Prevalence and distribution of foot lesions in dairy cattle in Alberta, Canada. J. Dairy Sci. 99:6828-6841. https: //doi.org/10.3168/jds.2016-10941.

Solano, L., H. W. Barkema, E. A. Pajor, S. Mason, S. J. LeBlanc, C. G. R. Nash, D. B. Haley, D. Pellerin, J. Rushen, A. M. de Passille, E. Vasseur, and K. Orsel. 2016b. Associations between lying behavior and lameness in Canadian Holstein-Friesian cows housed in freestall barns. J. Dairy Sci. 99:2086-2101. https://doi.org/10 3168/jds.2015-10336.

Solano, L., H. W. Barkema, E. A. Pajor, S. Mason, S. J. LeBlanc, J. C. Zaffino Heyerhoff, C. G. Nash, D. B. Haley, E. Vasseur, D. Pellerin, J. Rushen, A. M. de Passille, and K. Orsel. 2015. Prevalence of lameness and associated risk factors in Canadian Holstein-Friesian cows housed in freestall barns. J. Dairy Sci. 98:6978-6991. https:/ /doi.org/10.3168/jds.2015-9652.

Somers, J., and L. O'Grady. 2015. Foot lesions in lame cows on 10 dairy farms in Ireland. Ir. Vet. J. 68:10. https://doi.org/10.1186/ s13620-015-0039-0.

Tse, C., H. W. Barkema, T. J. DeVries, J. Rushen, and E. A. Pajor. 2017. Effect of transitioning to automatic milking systems on producers' perceptions of farm management and cow health in the Canadian dairy industry. J. Dairy Sci. 100:2404-2414. https://doi .org/10.3168/jds.2016-11521.

von Keyserlingk, M. A., A. Barrientos, K. Ito, E. Galo, and D. M. Weary. 2012. Benchmarking cow comfort on North American freestall dairies: Lameness, leg injuries, lying time, facility design, and management for high-producing Holstein dairy cows. J. Dairy Sci. 95:7399-7408. https://doi.org/10.3168/jds.2012-5807.

Westin, R., A. Vaughan, A. M. de Passille, T. J. DeVries, E. A. Pajor, D. Pellerin, J. M. Siegford, A. Witaifi, E. Vasseur, and J. Rushen. 2016. Cow- and farm-level risk factors for lameness on dairy farms with automated milking systems. J. Dairy Sci. 99:3732-3743. https://doi.org/10.3168/jds.2015-10414.

Whay, H. R., and J. K. Shearer. 2017. The impact of lameness on welfare of the dairy cow. Vet. Clin. North Am. Food Anim. Pract. 33:153-164. https://doi.org/10.1016/j.cvfa.2017.02.008. 